\title{
CSAE WPS/2010-39
}

\section{Live aid revisited: long-term impacts of the 1984 Ethiopian famine on children}

\author{
Stefan Dercon and Catherine Porter*
}

October 15, 2010

\begin{abstract}
In 1984, the world was shocked at the scale of a famine in Ethiopia that caused over half a million deaths, making it one of the worst in recent history. The mortality impacts are clearly significant. But what of the survivors? This paper provides the first estimates the long-term impact of the famine twenty years later, on the height of young adults aged 17-25 who experienced this severe shock in-utero and as infants during the crisis. Improving methodologically on other studies, famine intensity is measured at the household level, while impacts are assessed using a difference-indifferences comparison across siblings. We find that by adulthood, affected children who were under the age of 36 months at the peak of the crisis are significantly shorter than the older cohort, by at least $3 \mathrm{~cm}$. They are also less likely to have completed primary school, and more likely to have experienced recent illness. Indicative calculations show that this may lead to income losses of between $3 \%$ and $8 \%$ per year over their lifetime. The evidence also suggests that the relief operations at the time made little difference.
\end{abstract}

Keywords: Famine, human development, Ethiopia JEL Codes: I12, O12, J13, O15.

\footnotetext{
*University of Oxford. Email for correspondence: catherine.porter@economics.ox.ac.uk. The data used in this paper were collected by the University of Addis Ababa, the International Food Policy Research Institute (IFPRI), and the Centre for the Study of African Economies (CSAE). Funding for the ERHS survey was provided by the Economic and Social Research Council (ESRC), the Swedish International Development Agency (SIDA) and the United States Agency for International Development (USAID). Thanks also to Marcel Fafchamps, John Hoddinott and Alexander Moradi for useful comments on earlier versions. Any errors and omissions remain our own.
} 


\section{Introduction}

In October 1984 Ethiopia came to the developed world's attention in a dramatic BBC news broadcast from Tigray province in the Northern Highlands. The report showed pictures of starving people on a massive scale and galvanised citizens in Europe and the US into donating millions of pounds to relief agencies, and putting unprecedented pressure on their governments to send humanitarian relief. Up to a million people may have died, and many more were left destitute, making it one of the worst famines in recent history, and on par with the Chinese famine of 195961 in terms of mortality as a proportion of the population (O Grada, 2007). This paper examines what has happened to a sample of young people who experienced this extreme shock as infants by following up on their height attainment and other socio-economic outcomes twenty years on from the crisis.

There is a small but growing economics literature documenting the long-term impact of severe shocks and famines on subsequent human development. Almond (2006) finds long term health and human capital effects of the 1918 influenza pandemic on US data of those in utero during the crisis. Several papers investigate impacts of China's Great famine (Meng and Qian, 2009). Neelson and Stratmann (2010) provide recent evidence on educational impacts of the Greek famine of 1941. Alderman et al. (2007) find negative nutritional and schooling impacts from civil war and drought in Zimbabwe. Examining a positive rather than negative 'shock', Maluccio et al. (2008; 2009) show lasting improvements from an experimental nutrition intervention in Guatemala.

This paper is the first study to quantify the long-term consequences of one of Africa's most severe famines. We have access to longitudinal data of 479 young adults aged 17-25 years old in 2004, collected as part of a rural household panel survey across the country, initially started in 1989 as a study to document the impact of the famine. Our empirical strategy exploits the natural experiment inherent in the drought crisis underlying the famine, by comparing affected and non-affected siblings across cohorts both in-utero and in the first few years after birth with their older and younger siblings.

Methodologically, we can improve on earlier work in at least three ways, allowing more convincing causal inference. First, we have access to a measure of crisis intensity at the household level. Other studies of the impact of drought or famine in other countries have relied on shocks specified at the covariate level (e.g. Alderman et al., 2007), increasing measurement error in the measure of the crisis. The standard geographical identification of the shock also limits their ability to isolate the impacts of the drought from other factors. Our measure of the crisis at the household level is then likely to increase precision and offer more convincing causal attribution. Secondly, we are also able to examine impacts within households by using data on siblings. Using household fixed effects models allows us to eliminate any endogeneity bias that may have been caused by correlations between measured famine exposure and unobservable fixed household characteristics. Finally, famine survivors are typically from the top of the distribution determining survival (Deaton et al., 2008). This selection bias is then likely to attenuate the estimated impact of the famine. However, survival is strongly correlated with 
maternal and other family characteristics so the household fixed effects model considerably limits this selection bias as well.

We find that by adulthood, children who were under the age of 36 months at the peak of the crisis are significantly shorter than the older cohort who were at a less vulnerable age, by at least $3 \mathrm{~cm}$. Besides providing evidence on the impact of a specific famine on height, the paper contributes to the broader empirical literature on the importance of early childhood nutrition for subsequent childhood development (Strauss and Thomas, 2008). Actual height relative to genetic potential height can be seen as a measure of nutritional achievement, and taller people tend to be healthier, do better on cognitive tests, have more schooling and earn more (Deaton and Arora, 2009). We confirm the presence of some of these other socio-economic effects from the famine period: affected children are less likely to have completed primary school, and are more likely to have experienced recent illness. Using a Mincerian framework, we can show that these results are economically important for these young adults, leading to income losses of at least $3 \%$ per year over their lifetime.

In the next section we give more background on the 1984 famine, and introduce the data used in this paper. Section 3 offers the conceptual framework, and a review of the existing evidence on the impact of serious shocks and famine. It also discusses some of the problems with the current literature. Section 4 presents the econometric strategy, and section 5 discusses the results.

\section{Background and Data: The 1984 Famine}

Ethiopia has a long and troubled history of famines (Pankhurst, 1986a) including prolonged droughts and frequent severe rainfall failure. Since 1984 Ethiopia has appeared frequently in the worldwide media because it was on the verge of famine. The economy has experienced growth in the past decade, but seasonal hunger continues to be an endemic feature of life in many rural areas.

However, even against this difficult backdrop, the 1984 famine is still classed as one of the worst famines ever to have hit Ethiopia, and ranks amongst the worst in recent world history (O Grada (2007)). The impact of the famine in 1984 was deep and broad, though as is often the case in a complex emergency, statistics are sparse and unreliable. There is still no firm consensus on the number of deaths that it caused (see the debate in Pankhurst (1986b), Holcomb and Clay (1987)), though estimates range from half a million to over a million (the upper bound being the most popular media quotation). The main regions affected were Tigray, Eritrea and Wollo in the North of the country, although its effects were felt across the country. Warfare played a key role in causing famine in Tigray even before the drought occurred. Military offensives, aerial bombardment of markets, destruction of cattle and grain stores, burning of crops and tight controls on movements of migrants and traders combined to prevent the normal redistribution of grain and livestock surpluses in Northern Ethiopia, as documented by the Africa Watch Committee (1991). Kiros and Hogan (2001) examine excess mortality in Tigray during the years 1973 to 1991. They find the expected evidence of high mortality 
rates in the areas most affected by war and fighting across the board, though parental education reduced child mortality in areas that were marginally affected by conflict. Kidane (1990) calculates mortality based on interviews with resettlers, and suggests a total mortality estimate of 700,000 as reasonable. He further notes that the famine affected all socio-economic groups equally, a suggestion that is also made by Kumar (1990), who contrasts this with the 1974 famine that had a greater effect on less well off groups.

Relief in the form of food aid during 1984 was delayed due to political factors: a Marxist regime in power that was hostile to US and EU interests, and viewed the Ethiopia Relief and Rehabilitation Commission (RRC) as a relief agency with a history of overstating crisis statistics. Gill (1986) notes that during a donors' conference in March 1984 (when excess deaths were already apparent), many donors were sceptical of the information provided by the RRC, both on the needs of the population and the amount of available grain reserves.

A more independent measurement of the the drought shock would be through the examination of rainfall or vegetation data. Unfortunately there are no districtlevel official rainfall data available for many districts affected by the famine, including many of those covered by the our survey. Segele and Lamb (2005) have documented rainfall at a regional level over a period of 38 years (1961-99) and find that 1984 is extremely distinctive as the driest overall year - the Kiremt ${ }^{1}$ rains started relatively early but then dried up quickly, leading to an impossibly short effective growing season. They cite rainfall deficits of up to $94 \%$ in Wollo and the Rift Valley. Historical reports by the Ethiopia Relief and Rehabilitation Commission (RRC $(1984,1985)$ ) and other accounts (Gill (1986), Africa Watch Committee (1991), Webb et al. (1992), Jansson, Harris, and Penrose (1987)), further contextualise the development of the crisis. From these sources, we also find that 1982 was considered a 'normal year' of production in most regions, though no surveys are available to corroborate this. In April 1983, however the RRC report was alarming, and the main Meher crop ${ }^{2}$ season of 1983 showed evidence of widespread crop failure. 1984 was by all accounts a year of severe drought; in almost all regions the rains failed in the Belg (minor crop) season. The drought (from the rainfall data sparsely provided in RRC reports) can be said to have lasted through 1983 and 1984, and officially ended with the Kiremt rains that came in 1986.

The focus of the analysis in this paper is on the long-term impact of this serious shock by investigating nutritional and other outcomes 20 years later. We use a sample of 479 young adults (aged 17-25) from the sixth round of the Ethiopian Rural Household Survey (ERHS) in 2004. Their households have been surveyed by the University of Addis Ababa and the Centre for the Study of African Economies (CSAE) at the University of Oxford, as well as the International Food Policy

\footnotetext{
${ }^{1}$ The Kiremt rains account for 65-95 per cent of total annual rainfall in Ethiopia and tend to fall between June and September. In some regions (especially south of the Rift Valley) there are two sets of rain, the minor rainy season is the Belg rain in March/April though this varies by region.

${ }^{2}$ The Meher is the main crop of the year, harvested after the main Kiremt rains described above.
} 
Research Institute (IFPRI) since 1994. It builds on a survey in 1989 conducted by IFPRI to study the impact of the famine (Webb, von Braun, and Yohannes, 1992). The survey covers eighteen villages in fifteen communities ${ }^{3}$ from five regions. ${ }^{4}$ Within each village, random sampling was used. The households were resurveyed twice in 1994, again in 1995, and subsequently in 1997 and 1999. The sixth round of the survey was completed in 2004. The attrition rate for households is low, at around three per cent per round, reflecting the very low levels of migration in Ethiopia. The rate of attrition for individual household members is somewhat higher, as the survey followed households at a particular location, and not all individuals. Its likely consequences are discussed further below. Data on height are from the sixth round of the survey in 2004, twenty years after the famine. ${ }^{5}$ We also use data on the heights of these individuals as children, from the first round of the full ERHS survey in 1994, ten years previous. In 1995, the famine information collected in 1989 was supplemented by a careful recall module on droughts at household level. These data allow us to create a household level variable describing the intensity of the famine. A further discussion of the data, including the identification of the famine variable, and the child cohorts used in the empirical analysis is included in the econometric strategy.

\section{Theoretical framework and existing evidence}

Grossman (1972) conceptualised the idea of a 'health production function', which considers health in a particular time period to be a function of the initial health endowment (determined by both genetic characteristic, and environmental conditions in early life), and subsequent health inputs. Other important inputs to the health outcome are gender, age, community infrastructure, and the disease environment. Cunha et. al's (2006) review chapter on the economics of human capital formation provides a theoretical framework that echoes the nutrition literature and the focus on 'critical period programming'; Cunha and Heckman (2007) further develop theoretical aspects of this model. This multi-period model of child investment for a skills production function can include 'sensitive' or even 'critical' periods for producing abilities or skills. In addition, skills produced at an early stage augment the skills attained at later stages, and indeed improve their productivity (complementarity, or a multiplier effect).

Childhood is divided into several periods (or stages) before adulthood. Investment in the child during period $t$ is denoted as $I_{t}$ and the skill produced from the investment as $S_{t}$ for $t=1,2, \ldots, T$. Skills could contain a variety of abilities, we will simplify it to height as a proxy for nutritional achievement. This can be considered as proxying the ability to farm, carry wood and other manual tasks,

\footnotetext{
${ }^{3}$ These communities are called Woredas, or the equivalent of a county in the UK. They are further divided into what we term villages, officially called Peasant Associations (PAs), the lowest administrative unit.

${ }^{4}$ Although representative, 18 villages is clearly not enough to make strong inference about Ethiopia as a whole.

${ }^{5}$ A seventh round has recently been completed in end 2009, however anthropometric data were not collected.
} 
even signalling a potential healthy marriage partner. $S_{0}$ is the vector of initial skills at birth (though we may wish to define $t_{0}$ as being the point of conception to allow for the impact of shocks to affect the foetus in utero), and crucially, define the technology of skill formation (or growth) in a recursive fashion:

$$
S_{t}=f\left(I_{t}, S_{t-1}\right)
$$

where $f_{t}($.$) is increasing in \left(I_{t}, S_{t-1}\right)$ and is concave in $I_{t}$. The technology of skill formation in 1 determines complementarity or substitutability of investments in different time periods over time. We assume that skills in the second period augment productivity $\frac{\partial S_{2}}{\partial S_{1}}=\frac{\partial f_{2}}{\partial S_{1}}>0$, and that higher levels of stocks in skills for the first period increase the productivity of investments in period $2: \frac{\partial^{2} f_{2}\left(I_{2}, S_{1}\right)}{\partial I_{2} \partial S_{1}^{\prime}}>0$. In the extreme case of perfect complementarity, investments in period two cannot compensate for the lack of investment in period one. ${ }^{6}$ In sum, Cunha et al. assert that early child investments must be distinguished from late child investments, and, that an equity-efficiency trade-off exists for late investments, but not for early investments. The extreme case is a kind of 'Leontief technology' in terms of investments over time; non- or reduced development at one stage of the life cycle could lead to a 'bottleneck' where it is difficult to develop further.

The model outlined above shows how a severe shock in a critical period of development (usually under the age of five) may lead to persistent lower levels of achievement in human capital, and is the inspiration for our empirical analysis. However, outcomes for health, nutrition and economic success can be mutually reinforcing (and thus, endogenous) and correlated with parental preferences for child development. Achievement levels are in part genetically determined, but can also be influenced by environmental factors (including in utero experiences). A key preoccupation of the economic literature has thus been to try and find exogenous sources of variation in nutrition inputs.

The literature in medicine and epidemiology contains a large number of articles on the correlation between childhood characteristics and adult anthropometric outcomes, though they are less successful at documenting causality (Karlberg and Luo (2000), Rona (1981), Ruel et al. (1995) and for a commentary, Gunnell (2002)). The 'foetal origins hypothesis' incorporates a substantial body of epidemiological and biological research that adult outcomes (especially in terms of health) are strongly influenced by experiences in the womb (for an overview see Barker (1992) and Godfrey and Barker (2000)- the latter summarises experimental evidence for rats). There is also evidence that the potential for catching up on lost growth is limited beyond the age of three as summarised by Martorell et al. (1994). Medical evidence appears to show that genetic factors play a lesser role than environmental factors or nutrition in explaining height differences across groups (Habicht et al. (1974)), though recently the complex interplay between genetics and environment has been highlighted as an important determinant of skills development (for a review of the evidence, see Rutter (2006). Taken together, this literature then suggests that critical ages for a child appear then to be especially

\footnotetext{
${ }^{6}$ Thus the skill level attained in period 2 is restricted by period one deficiency.
} 
in utero and up to the age of about 36 months, as catch-up afterwards is limited, providing the basic hypotheses for much of the empirical literature on the long-term impact of shocks.

Experimental studies have been able to look at the impact of positive shocks, and found long-term postitive impacts of early childhood nutritional improvement. For example, Maluccio et al. (2009) show lasting human capital improvements from an experimental nutrition intervention in Guatemala. Extreme negative shocks do not have the luxury of the presence of experimental designs. At best, they can use natural experiments such as offered by large droughts and other crises. Strauss and Thomas (2008) note that relatively few economic studies have identified a long-term causal impact of an extreme event experienced in childhood, given the high data demands for such an exercise, though this can be a fruitful line of research in terms of building the evidence base for the economic benefits of preventing such crises.

Meng and Qian (2009) investigate the China famine of 1959-61 comparing birth cohorts using outcome data collected as part of a cross-section survey in 1989. They identify the famine shock at the county level and argue that the specific circumstances in China limit the presence of confounding factors. They find substantial impacts of the famine for those who were young at the time, in terms of height, and other socio-economic outcomes. They use quantile regression analysis to overcome the possibility of a selection bias in their results, as survivors of the crisis are likely to be children otherwise in the higher part of the health distribution (Deaton et al., 2008). Neelson and Stratmann (2010) find educational attainment was affected by the Greek famine of 1941, especially for those who experienced the crisis as infants. Maccini and Yang (2009) show that even nonextreme variability in rainfall during early life has a significant effect on a large number of future adult outcomes in Indonesia. Serious epidemics have also been studied. Almond (2006) found a substantial long-run effect of the 1918 influenza pandemic on US data of those in utero during the crisis, though notes that it is impossible to separate the effect of the illness from other macroeconomic events of the time. Banerjee, Duflo, Postel-Vinay, and Watts (2007) estimate the long-term impact of disease around the time of birth on adult health outcomes using state level data from 18th century France. They find a significant impact on height, but not on life expectancy or morbidity. Dercon et al. (1996) use longitudinal data on initially non-orphaned children to study the impact of orphanhood in Tanzania in areas seriously affected by HIV-AIDS. Controlling for pre-orphanhood observable child and family characteristics, they find that orphanhood decreases height and educational achievements in adulthood. Civil war has also been studied as a source of exogenous variation to identify extreme events. Alderman et al. (2007) use maternal fixed-effects and instrumental variables to study two cohorts of children who were alive during a civil war and drought in Zimbabwe. They examine nutritional and schooling outcomes for children who experienced shocks at a vulnerable age (12-24 months) and find that these children are significantly smaller and complete less schooling; using typical rates of return to education they translate this to a loss in lifetime earnings of seven per cent. 
While generally persuasive, these and other studies are not without their potential problems (for a review and critique of several of the studies quoted, see Strauss and Thomas (2008)). For example, many rely on variables defined over relatively large geographical entities for distinguishing the affected and non-affected within a particular cohort, contributing to measurement error and attenuation bias, as well as risking that confounding factors cannot be isolated. In our study, we can define the famine shock at the household level rather than relying on a geographically defined shock. This is nevertheless opening us to criticism that may precisely be avoided by using geographical comparisons: the famine shock, defined at the household level, may be correlated with unobservable household factors, as certain households may be more likely to be affected, creating endogeneity bias. Measurement error, correlated with unobserved household characteristics, could cause further bias. Faced with a similar problem when studying orphanhood and its impact on outcomes at adulthood, Dercon et al. (1996) control for a wide variety of pre-shock child and household characteristics. Here, we can do better, and also control for unobserved household heterogeneity by identifying all impacts using within-household variation. Strauss and Thomas (2008) criticise some of these studies further by noting that the impact of some of the crises likely lasted longer than the time-period specified (e.g. as infrastructure needed to be rebuilt after a civil war). This is definitely an issue for our study, as the Ethiopian famine took place within the context of a mostly relatively localized but nevertheless intense civil war, so that life in any case did not return to normal immediately after the 'end' of the famine. In any case, this would bias us against finding any results offer one reason that our findings would be a lower bound.

\section{Econometric strategy}

We aim to test whether the Ethiopian Famine of 1984 affected children who were at a vulnerable age - in utero or newly born up to the age of 36 months - at the time of the drought shock. The empirical analysis is guided by the model outlined above, but uses a reduced form specification, given that we do not have specific information on other inputs in early childhood; our key question is to identify the long-term impact of the famine. Equation 2 provides the basis for our test.

$$
H_{i}=\beta+\sum_{c=2}^{C} \beta_{f c} \operatorname{fam}_{h} \rho_{c}+\sum_{c=2}^{C} \beta_{c} \rho_{c}+\gamma_{h}+e_{i}
$$

Our main focus is height $H_{i}$ for each individual $i$ at adulthood in 2004, but we will use a similar set-up for other outcome indicators, such as education and morbidity. We will compare the height attainment of a number of age cohorts $c$ defined across all the young adults aged 17 to 25 in 2004. In particular, as different age groups are likely to have been differentially affected, we will specify a spline function across $C$ cohorts. We consider four cohorts, with the oldest group as the base group. We observe a household level famine shock fam $\mathrm{f}_{h}$ which is interacted with the age (cohort) of the individual at the time of the shock. 
$\beta_{f c}$ will measure the impact of the famine on children of cohort $c$ living in a household directly affected by the drought shock. If the impact of the famine went well beyond cohorts living in families directly affected by the famine, then this would be picked up by values of $\beta_{c}$, defined relative to a base group cohort that was born well before the famine, and past the critical first few years of life. Our identification is strengthened by including $\gamma_{h}$, capturing all household effects, ensuring that comparisons are done within cohorts of siblings living in the same family. ${ }^{7}$

Our specification, not least our ability to use household fixed effects, helps inference considerably, compared to other studies. Crucially, it allows us to disentangle famine exposure of a particular cohort from unobserved household heterogeneity correlated with famine exposure. However, and if anything, we still expect that our effects may be biased downwards, giving lower bound estimates of the long-term impact of the famine and making our (considerable) results even more striking. A standard problem in inference on the impact of large crises is positive selection into the sample of those who survived despite being at risk during the critical period. The drought and famine will have had a permanent impact on a large number of children through their early mortality. Stronger, healthier children with better genetic health endowments are more likely to have survived. In addition, these children could have subsequently benefited from reduced cohort sizes due to lower fertility during the famine, or high levels of child mortality at that time. This positive selection would lead to a downward bias in the estimated impact. Importantly, however, evidence from epidemiological studies during famines and other crises in Ethiopia, Guinea-Bissau and Cambodia highlight the strong predictive power of household and parental characteristics such as wealth and parental education in explaining excess mortality during such crises (Kiros and Hogan, 2001; Nielsen, Jensen, Andersen, and Aaby, 2006; Hong, Mishra, and Michael, 2007), so that the use of household fixed effects will reduce the likely bias. Our identification strategy for the famine effects depends crucially on two elements: a household-specific drought shock and the appropriate identification of cohorts for comparison. We discuss each in turn.

\subsection{Identification strategy: drought shock}

As noted in the introduction, the famine peaked in the year lasting from October 1984 to September 1985 (Ethiopian calendar year 1977). Continuing drought meant that many harvests failed towards the end of 1985, and the end of the crisis is seen by most accounts to be towards the end of 1986 when harvests were at almost normal levels. In this section we use the available data to confirm this period as an identifiable drought shock. We identify the drought shock at the household level. In 1995, as part of an in-depth investigation of the 1984-85 famine and other serious shocks, their responses and experiences of relief efforts,

\footnotetext{
${ }^{7}$ In Ethiopia, households are typically organised as nuclear families, with parents living with their children, and married children leaving the homestead. The result is that despite high fertility, households are relatively small, on average below 6 members per household.
} 
households were asked to report whether they experienced serious droughts in the last 20 years. $^{8}$

$77 \%$ of all households in the sample cite drought as one of the shocks that has affected them in the past 20 years, in a questionnaire that included a variety of potential crises such as; too much rain, pest and diseases, harvest losses in storage, frost and hailstorms. Respondents were asked to cite the three worst crises of the last twenty years. Drought is by far the most common shock. Of those who cite drought, the majority (72\%) mentioned the years 1983-85 (1975-77 EC), and 60\% cite $1984-85$ as their worst year when asked to name the worst three years. ${ }^{9}$

Table 1 column (2) shows the region of each village. The third column (3) shows that over $80 \%$ of people mention drought as a problem in approximately two thirds (eleven) of the villages, and the fourth column shows that in these villages 1983-85 is the clear mode. We include the 1984-85 specific drought shock at the household level (column 5). Note that the famine shock variable is collected at the household level, ten years prior to the final height measurement we use as the dependent variable in 2004, and the question referred to the households' experiences, not those of any one child, limiting respondent bias correlated with the height potential of one child relative to another is unlikely. At the same time, despite being based on recall, the underlying question here is nevertheless simple, and refers to one of the most serious crises in these families' life time, rendering measurement error and its implied attenuation bias less likely. Also, even though drought is by its nature a covariate shock, affecting specific geographical areas, it does not affect all individual households in a community in the same way, depending on the specific livelihood, type of crops grown, access to alternative water sources for water harvesting, and, given the mountainous nature of many of the villages and its implications for the micro-climate, the exact geographical location. Only in a few villages, all villagers reported to be affected but this is a plausible outcome.

\subsection{Identification strategy: affected and control groups of children}

Having carefully identified that the main shock in question occurred in 1984-85, we are particularly concerned to identify the impact on very young children, affected by the famine in utero or in early childhood. We take as the reference group children who are born in the years around the famine, i.e. those who are aged 1725 in 2004 (aged up to 6 years old in 1984-85, and born up to two years after that). We used the age data collected during the first round of the longitudinal study in 1994. We found there is considerable rounding; for example $46 \%$ of children are reported to have a rounded age (e.g. 12 years and zero months) with heaping around age 10 and 12. This will add to measurement error in the identification of

\footnotetext{
${ }^{8}$ Specifically, the question asked in the third round of the ERHS is "In the last 20 years has the household suffered a substantial loss of harvest through any of the following [list of potential crises]?" The households that responded affirmatively for drought were asked to list the three worst crisis years. Ethiopian calendar year 1977 corresponds to 1984-85 Georgian calendar.

${ }^{9}$ This is very similar to the full sample of ERHS housholds
} 
the effects of the famine, but again, as we are making comparisons within families, it is unlikely to be a source of systematic bias but rather more attenuation bias, reducing the chances of finding an impact of the famine.

We wish to estimate an age fixed effects model as an econometric strategy, therefore we take 24 month cohorts of the sample of children born during the drought; just after the drought; and children who are 24 months years older and younger than them - which gives us four cohorts of children aged 6-14 in 1994 or round one of the dataset, ten years after the drought. Table 2 shows the construction of the cohorts, and also notes the key events in the timeline of the crisis. The youngest cohort are born between September 1985 and September 1987, after the peak of the famine had subsided. We expect these children in principle to be slightly less affected as they would be breastfeeding in the latter part of the crisis, though it is possible that some effect may pass through the mother after a long period of undernutrition just before the pregnancy. They are aged $17-18$ at the time of measurement in 2004, and therefore possibly still growing relative to the other cohorts considered. ${ }^{10}$ The next cohort are born between September 1983 and September 1985. This is the peak of the famine as seen in the literature review, and these children are either born directly into the midst of the suffering, or are in utero for the suffering periods. They are aged 19-20 years in 2004. The second oldest cohort are born September 1982September 1984, and are therefore aged 13-36 months during the 'peak' famine year of 1984-85. We might a priori expect these children to be the most affected for two reasons: firstly, they were at one of the most vulnerable ages to experience a nutrition shock (having probably stopped breastfeeding around the time of the peak crisis), and also, in some of the villages (particularly the three in the North of the country) the food crisis was ongoing from around 1981 due to civil war, therefore they may have lived through a longer period of suffering and nutritional deficit. This cohort are aged 21-22 years in 2004. The oldest cohort are born between September 1979 and September 1982. ${ }^{11}$ This cohort are thus born before the main famine began, and were at a more 'robust' age when the famine struck (over 36 months). This cohort are aged 23-25 in the 2004 survey, and forms the base group for the analysis.

\subsection{Outcomes and Descriptive Statistics}

To measure the stock of nutritional achievement of the cohorts when they are young adults in 2004 we use their height in centimetres. As a check, we also use information on height ten years previous (i.e. ten years after the famine) in 1994. As the cohorts would still be growing at this point (and possibly into the adolescent 'growth spurts') we calculate the height-for-age z-score (HAZ), which are correlated with long-run investments in child nutrition (i.e. the 'stock' of

\footnotetext{
${ }^{10}$ As adolescents may still have growth spurts up to the age of 18 , we will have to be cautious in interpreting the findings, while heterogeneity in the end year of growth will increase the variance of the estimates of the famine impact for this cohort.

${ }^{11}$ We include three years in this cohort in order to maximise the sample size.
} 
health). They show the height of the child relative to an international reference group of healthy children. We use the WHO Reference 2007. ${ }^{12}$ As other measures of human capital at adulthood in 2004 we use weight measurements to construct body-mass-index (BMI) and a question on recent health. Specifically, the health question asks whether the person has been ill in the past four weeks to the survey (in 2004). Evidence on the impact of nutritional shocks on BMI may be complicated however, recalling the results above that sometimes children or those in utero at the time of the shock actually end up more likely to be overweight (and have high blood pressure) than others, due to physiological changes that make the body more efficient at processing available nutrition. ${ }^{13}$ We utilise available information on the highest grade that the cohorts achieved in schoolaround twenty per cent have never attended school and half have not achieved full primary education or above. Basic summary statistics are reported in table 4 . Average heights of each cohort, separated into the affected and unaffected groups is reported in table 3, and we note that we find significant (at 90\%) differences only in the oldest group, where the famine affected group are taller. This is the group where children were over the age of 3 when the famine occurred, suggesting that the potential height of children from famine-affected households is higher.

\section{Results and Discussion}

\section{$5.1 \quad$ Results}

Table 5 shows the impact of the famine on the young adults in 2004. As discussed above, we have information on 479 individuals aged 17-25 in 2004. Table 4 shows means and standard deviations of the included variables. Our specification is a within-household model as outlined in equation 2 . We include the age cohorts, and their interactions with the shock variable, as well as controls for sex of the child and its birth order. Standard errors are adjusted for cluster-specific heterogeneity, except for the logit specifications in columns (5) and (6).

Column (1) shows the results testing the impact of the shock on height in centimetres twenty years after the event. The cohort dummies overall show a significantly lower height for the younger cohorts compared to the oldest (the base group). While this could reflect a general impact of the famine on the entire cohort, this is likely to be related to the fact that they may still be growing by the time of the survey, especially the youngest cohort, for whom the effect is largest. All the interaction effects between the shock and cohort are negative, suggesting further losses for those children from vulnerable cohorts living in families specifically affected, although it is only (strongly) significant for those aged 2 or 3 during the famine crisis. For this group, the overall impact of being affected relative to the (older unaffected) base group is about $3 \mathrm{~cm}$ (or about $6 \mathrm{~cm}$ shorter compared to the comparison group of the unaffected of the same age, but this group is apparently about $3 \mathrm{~cm}$ taller compared to the oldest group, so the overall

\footnotetext{
${ }^{12}$ Raw data at http://www.who.int/growthref/ last accessed Feb 23rd 2010.

${ }^{13}$ See Strauss and Thomas (2008) for further discussion and references.
} 
impact of the famine is its sum or $3 \mathrm{~cm}$ for those affected amongst those 2 or 3 years old). A test of joint significance of the famine interactions showed that they were jointly significant from zero and we could not reject that they were equal to each other (significant at $10 \% F(2,16)=2.72$ ). Column $(2)$ shows the equation imposing the restriction of equal coefficient for all age groups (i.e. all children below 4 in the crisis, including those in utero). With this restriction, the overall cohort effects are disappearing (except for the youngest cohort) and on average the impact of the drought on all cohorts is strongly significant and $3.9 \mathrm{~cm}$, which is approximately a third of the standard deviation of the sample.

In sum, we find a strong and significant effect of the drought and famine shock of 1984-85 on young children and children in utero at adulthood. Unpacking this effect by age cohort, the effect is specifically strong and significant for those 2-3 years of age at the time of the famine. This is in fact the group that we would have expected to experience a substantial and even the most substantial impact from our review of the literature - those who were just above breastfeeding age, but still not quite at an age to be robust to shocks.

As this group of children was followed since 1994, we can check whether these effects were persistently visible throughout childhood (although the sample is slightly smaller as some children where not found at home at the time for the height measurement). Column (3) uses height-for-age z-scores (HAZ) in the first round (1994, or ten years after the famine) we find again negative coefficients for all the famine interaction terms, although it is only significant for the youngest group at this point in time in uteroat the time of the famine). Imposing the joint restriction as above was not quite significant (p-value of 0.107); trimming the sample for five outliers finds this restriction significant. In general, the higher standard errors may reflect the fact that for this age group (6-15 years), there is bound to be more noise in the patterns of growth, as children are experiencing growth spurts at different ages. The evidence remains suggestive of relevant effects of the famine, also visible 10 years after the famine. The size of the impact with the restriction imposed was 0.61 , or about $40 \%$ of a standard deviation in the data.

The data also allow us to look at other outcomes. The Body Mass Index (BMI) offers a simple measure of short-run health linked to nutrition. Some studies on the Dutch and Chinese famine have found that those who had suffered during famines showed signs of obesity in later life, possibly as certain organs failed to develop properly, with stronger evidence for women than men (Ravelli et al. (1998), (1999), Luo et al. (2006)). For example, in the case of the Chinese famine of 1959-61, Luo et al. (2006) found that women born during the famine were more likely to be overweight in adulthood. We can test this result in our data. The BMI results in column (4) show no significant famine effect either for a single cohort or jointly. Interestingly, the coefficients on the interaction terms are all positive - suggestive of the effect found in the studies quoted above, although imprecisely estimated. ${ }^{14}$ In any case, these findings suggest that while those affected by the famine are shorter, they do not have lower BMI when young adults.

\footnotetext{
${ }^{14}$ As discussed further below, we did not detect any differences between men and women.
} 
The famine also appears to have other long-term impacts on the children affected in early childhood. In column (5) we show the result that the likelihood of finishing primary school is also significantly lower for the cohort of famineaffected children aged 2-3 years in the crisis, echoing the results from the height regressions. Note that the sample size drops by over half due to a lack of variation in outcomes within households, as we are using the conditional fixed-effects logit model which drops such observations. ${ }^{15}$ As this is a reduced-form estimator, it is difficult to claim that the mechanism of lower school achievement within the family is linked to the cognitive effects of poor nutrition in early childhood, but the consistency with the results in column (1) can definitely not discount this interpretation. Without a further model and evidence of within-household investment in human capital, this cannot be established conclusively.

Finally in column (6) we present a conditional fixed effects logit result for a dummy variable measuring morbidity: whether the person had been ill in the four weeks prior to the survey in 2004. The sample size drops quite dramatically at this point (as the scope for variation within households becomes more limited) but interestingly we see significant results for the cohort aged 0-1 in the famine. A test for joint significance of all three famine interactions was marginally rejected $(\mathrm{p}=0.109)$, but imposing a restriction that the coefficient was the same for the two older age groups (i.e those aged $0-3$ in the famine) gave a coefficient of 2.36, significant at $10 \%(\mathrm{p}=0.08)$. This is very striking, as morbidity measures are generally weak discriminators for health: here we find that famine appears to be linked with significantly higher morbidity 20 years later.

\subsection{Robustness and Further Interpretation}

For all the specifications, we also explored whether there were any gender-specific effects across all the results reported. We find that there is never a jointly or cohort-specific significantly different effect for girls and boys due to the famine. For example, in the height regression in column (1), testing a different boy-girl effect in equation (6), we included a girl-specific different effect in the famineage interactions. The F-joint significance test was not significant $(\mathrm{F}(3,16)=$ $0.17, \mathrm{p}=0.92))$. A number of robustness tests also showed no differences in the results. Trimming the sample did not change the results for the first four columns significantly. Also we acknowledge that the sample size changes in the various columns due to some missing data, and we have attempted to maximise the sample size in all specifications by including all individuals with non missing data. We ran columns (1-4) using a common sample of 419 individuals and this did not alter any results significantly. The results are also not driven by opportunistic definition of the relevant period for the famine shock. For example, repeating the analysis by replacing the famine shock as defined here referring to the peak period (in 198485) to a broader period 1983-85 (i.e. households that also reported this period as their worst period) made no difference to the results. We report in column

\footnotetext{
15 A regression using the ordinal variable of final school grade completed did not show any significant effects.
} 
(0) of table 5 the results without the household fixed-effects as a reference, and find a positive significant coefficient on the famine shock. Hence our fixed effects estimates are actually showing a stronger impact on the younger cohorts. This is consistent with better off households being affected.

Qualitative work in some of the communities (Bevan, Kebede, and Pankhurst, 1994) has suggested that the crisis may have started earlier in Tigray and Wollo, and the three communities covered by the survey in these regions, as rains may have failed in 1981-82, and also because these were the specific regions most affected by the conflict. ${ }^{16}$ The result is that for these three communities (Haresaw, Geblen and Shumsha), the use of the older cohort as the base group may not be providing an appropriate counterfactual, potentially underestimating the impact the famine as a result. As a robustness test, we performed the analysis also dropping these communities (40 observations) and the results were unchanged.

Analysing long-term impacts of events decades earlier may be affected by serious attrition problems of which survival bias is only one. As the data in 2004 come from a longitudinal data set, we can pursue the likely impact of any other, post-famine, attrition in the data. For example, even if children survived, differential strength and intellectual ability may have affected migration or marriage of those affected and those not affected differentially. It may be that those not affected by the famine may have more labour market opportunities and have left the village, while those affected and weaker may be in the sample. This could result in further bias, but this time implying that our results may overstate our findings, if among the non-affected the stronger have been able to leave. Here, the first round of the longitudinal survey, 1994, helps to explore this, as this sample collected household membership data on all in the household at that time, with children too young to live away from home. ${ }^{17}$

Relative to 1994, we are faced with considerable attrition for the age-specific sibling sample used in this study. Of the initial sample of the relevant age-cohort in $1994,21 \%$ of the children moved away and about 3 percent died. In our actual analysis, we lose another fifth of the observations, as our identification requires at least 2 observations per household. Missing height measurements of children or of relevant siblings adds further to attrition. However, there seems no evidence that this attrition post-1994 is systematically affecting our results. In particular, we estimated a probit on remaining in the sample using the same correlates as in table 5. We found a significant difference in the probability of being in the sample between cohorts, with those who were younger predictably being more likely to be in the sample, and females less likely to be observed. Crucially, however, for the famine interactions, there were no significant differences either individually or

\footnotetext{
${ }^{16}$ Intensive qualitative research in the other communities covered by the survey has suggested that the civil war and conflict in Ethiopia was not affecting them until much later, in the late 1980s, contrary to the communities in Wollo and Tigray.

${ }^{17}$ In 1994, the sample would have been too young to live independently away from home. In recent times, children often live away from home for educational reasons, as secondary schools are only in towns. However, in 1994, few did so in rural Ethiopia. Net primary school enrolment rates in the sample were only around $20 \%$; and below $10 \%$ for secondary education. Even so, these children would have been recorded as in the household.
} 
jointly $(\mathrm{p}=0.35)$; those affected were not more or less likely to be observed in the sample. We conclude that despite significant attrition, there is nothing systematic that would bias our analysis.

All these long-term impact estimates are net of coping strategies that households may have undertaken in order to mitigate the short-term impact of the shock on household consumption. They are also net of any food aid or other relief that may have taken place. We have some information on whether food aid was received during this period, as well as how the household responded to the crisis. In 1994, detailed data were collected recalling this traumatic period. Contrary to impressions created by the media during famines, few made it to feeding camps (under 5\%). Food aid targeting is always difficult, as the general equilibrium effects of a famine mean that all face some problems, such as those linked to rising food prices. Unsurprisingly, in view of what happened, we find relatively imprecise targeting: during 1984-85, when food started being distributed, $32 \%$ of those affected by the drought shock obtained some food aid, compared to $25 \%$ of unaffected. Still, amounts received per capita were considerably higher for those reporting the shock compared to the others. Median receipts for both groups is zero, and a mean $87 \mathrm{~kg}$ per affected household is relatively little for a whole year. Imperfect targeting of aid, and the scale of the crisis meant that households had to resort to costly coping strategies. Of those affected by the crisis, $91 \%$ cut back on meal sizes, compared to $65 \%$ of those not reportedly affected; $61 \%$ of those affected ate wild foods they would not normally eat (29\% of those unaffected), and $48 \%$ sold valuable assets (24\% of those unaffected). ${ }^{18}$

Is there any evidence that the food aid reduced the long-term impact of the famine on our cohorts? Non-random placement of famine relief makes this a difficult topic, so at most, we can only provide some indicative evidence. We interacted the cohort and cohort-famine shock variables with a dummy for receiving food aid (there is no separate food aid dummy as this is a household level variable, captured by the household fixed effect). None of the interaction effects were significant, neither individually, nor jointly across the specific groups affected by the famine $(p=0.67)$ or across the cohorts $(p=0.41)$. Similarly, using amounts of food aid received, there were no significant interaction effects. We have to be cautious in interpreting these results: it could mean that food aid was irrelevant on average; for example, it was just too little to make any difference for those in those young children at a vulnerable age. By lack of an appropriate counterfactual, it could also mean that it was so well targeted that those receiving food aid would have been worse off than those not receiving it, and that now they have equal opportunities. In view of the evidence on targeting described above, and the key findings of this paper, this would seem rather unlikely. On the basis of our evidence, it would be hard to defend that this was a well-handled successful famine relief operation.

What are the implications of this loss in human capital for the affected cohort?

\footnotetext{
${ }^{18}$ The relatively high percentages of those not reporting to be directly affected by drought but still using particular coping mechanism is a reflection of the likely general equilibrium effects, making our estimates of impact again more likely to be a lower bound.
} 
As noted in the literature review, a number of studies have found a positive and significant relationship between height and earnings, in many country contexts. In table 7 we present some simple Mincerian regressions of total annual income, using a sample of household heads from the 2004 round of the ERHS (i.e. the full sample and a larger sample than the young adults we could trace back to the famine). We include village fixed-effects, gender of the head, age of the head and its square, schooling of the head and household size and composition variables. ${ }^{19}$ We find that a $1 \mathrm{~cm}$ increase in height results in approximately $1 \%$ increase in annual income. On top of this, income is (predictably) highly correlated with schooling, increasing $7 \%$ per school grade attained. In table 5 (column (5)) we found that the affected cohort were also significantly less likely to have finished primary school. In column (2) of table 7 we find that completing primary school is correlated with higher annual income of $17 \%$. Whilst we do not consider these as causal relations due to the incomplete model, they are indicative of the kinds of impacts that might be felt as our sample age and become household heads themselves. Repeating the analysis in column (5) in table 4, explaining whether primary school had been completed, using a linear probability model with household fixed effects, we can be more specific on its implications. It suggests a (significant) impact for the affected 2-3 year olds of -0.31 , so using column (2) in table 5 , we find a further impact on income of $5.4 \%$ for the affected group due to the famine, yielding a total income decline of $8.3 \%$ that can be linked to the famine.

\section{Conclusion}

Nutrition in early childhood is a strong determinant of height at adulthood. Height at adulthood has been shown to be a strong determinant of earnings and other measures of 'success' in life. This paper contributes to a small body of economic evidence on long-term impacts of extreme events experienced in early childhood, by providing the first estimates of the impact of one of the biggest famines to have hit Africa, the case of Ethiopia in 1984.

The use of a family-specific famine shock allows us to distinguish this effect from a more general macro-effect affecting all in particular communities, while the within-household estimator ensures that any household-level heterogeneity correlated to famine exposure is not biasing our results. The effects are large, but could still even be only a lower bound. First, there could still be selection into the sample of probably stronger children, if mortality rates were higher for shorter children. While mortality is considerably determined by family and community characteristics, and therefore controlled for by the household fixed effects regres-

\footnotetext{
${ }^{19}$ Note that in the ERHS there are very few people who work for wages (approximately 350 with non-missing values), as most people are occupied on the family farm. Whilst this is therefore clearly an incomplete model of income generation, our aim is to provide some basic correlations of the relationship between height of the household head and income generated by the household as a whole. As a robustness check we also estimated the same equation for crop income, and the results were very similar. Table 6 shows descriptive statistics for the sample of household heads.
} 
sor, within family effects could have led to relatively stronger children surviving. Second, the comparison group is other children who were alive at the time of a severe famine, despite their household not reporting it as the worst year- it is highly likely that every village in Ethiopia was affected by this to a greater or lesser extent, and if so this will make the difference between affected and nonaffected children smaller. Third, we have to contend with some heaping of age, and the drought instrument is relatively 'blunt' in the sense that we cannot be more precise (e.g. to the month) about the length of the shock. These measurement issues cause attenuation bias in the estimates, making it less likely that we find any effects.

The results presented show that children who experienced but survived a large scale and severe nutritional shock at a critical period in their development are discernibly smaller than their peers when measured twenty years later. We find that those in the particularly vulnerable age of 12 to 36 months at the height of the famine were about $3 \mathrm{~cm}$ shorter due to the famine. We cannot reject that all those in utero and those below the age of 36 months were all similarly and significantly affected. These effects are substantial. The loss can be compared it to the findings summarised in Strauss and Thomas (2008) that developing countries gained an average of $1 \mathrm{~cm}$ in height per decade. However the famine impact in Ethiopia is also in line with findings from other serious famines. For example, the results on China quoted in Meng and Qian (2009) suggest on average a height reduction of $2.8 \mathrm{~cm}$ due to the 1959-61 famine, with further effects on educational achievement. We also find that those vulnerable and affected at the time of the famine are less likely to have finished primary school and may very well be more likely to be ill. Indicative calculations show that this height deficit could lead to reduced income of at least 3\% per annum, and even up to $8 \%$ per year, if we consider that they are less likely to have completed primary school. Our analysis also suggests that famine relief in the form of food aid did not appear to have been effective in reducing impacts on the most vulnerable children, despite massive aid efforts. This study thus adds to a body of knowledge on the long-term impact of severe shocks, and underlines the importance of swift nutritional interventions in complex emergencies, specifically targeting children who are at a critical stage in their development.

\section{References}

Africa Watch Committee (1991): Evil days : 30 years of war and famine in Ethiopia, Africa Watch report. Human Rights Watch, New York ; London.

Alderman, H., J. R. Behrman, and J. Hoddinott (2007): "Economic and Nutritional Analyses Offer Substantial Synergies for Understanding Human Nutrition," J. Nutr., 137(3), 537-544.

Almond, D. (2006): "Is the 1918 Influenza Pandemic Over? Long-Term Effects of In Utero Influenza Exposure in the Post-1940 U.S. Population," Journal of Political Economy, 114(4), 672-712. 
Banerjee, A. V., E. Duflo, G. Postel-Vinay, and T. Watts (2007): "Long Run Health Impacts of Income Shocks: Wine and Phylloxera in 19th Century France," Discussion Paper 12895, NBER Working Paper.

BARker, D. J. P. (1992): Fetal and infant origins of adult disease. British Medical Journal, London.

Bevan, P., B. Kebede, and A. Pankhurst (1994): "Ethiopian Village Studies," Discussion paper, Centre For the Study of African Economies.

Cunha, F., And J. J. Heckman (2007): "The Technology of Skill Formation," American Economic Review, 97(2), 31-47.

Cunha, F., J. J. Heckman, L. Lochner, and D. V. Masterov (2006): "Interpreting the Evidence on Life Cycle Skill Formation," in Handbook of the Economics of Education, ed. by E. Hanushek, and F. Welch, vol. 1 of National Bureau of Economic Research Working Paper Series. Elsevier, North-Holland.

Deaton, A., and R. Arora (2009): "Life at the top: the benefits of height," Economics and Human Biology, 7(2), 133-136.

Deaton, A., C. Bozzoli, and C. Quintana-Domeque (2008): "Adult Height and Childhood Disease," Demography, 46(4), 647-669.

Dercon, S., J. De Weerdt, and K. Beegle (1996): "Orphanhood and the Long-Run Impact on Children," American Journal of Agricultural Economics, $88(5)$.

GiLl, P. (1986): A year in the death of Africa: politics, bureaucracy, and the famine. Paladin, London.

Godfrey, K., And D. Barker (2000): "Fetal nutrition and adult disease," American Journal of Clinical Nutrition, 71, 1344S-1352S.

Grossman, M. (1972): "On the Concept of Health Capital and the Demand for Health," Journal of Political Economy, 80(2), 223-255.

Gunnell, D. (2002): "Commentary: Can adult anthropometry be used as a 'biomarker' for prenatal and childhood exposures?," International Journal of Epidemiology, 31(2), 390-394.

Habicht, J. P., R. Martorell, C. Yarbrough, R. M. Malina, and R. E. KLEIN (1974): "Height and weight standards for preschool children: How relevant are ethnic differences?," The Lancet, 6, 611-615.

Holcomb, B. K., and J. W. Clay (1987): "The Politics of a Famine Report: Rejoinder to Richard Pankhurst," Anthropology Today, 3(1), 10-12.

Hong, R., V. Mishra, and J. Michael (2007): "Economic Disparity and Child Survival in Cambodia," Asia Pac J Public Health, 19(2), 37 - 44. 
Jansson, K., M. Harris, and A. Penrose (1987): The Ethiopian famine. Zed, London.

Karlberg, J., and Z. C. Luo (2000): "Foetal size to final height," Acta Paediatrica, 89(6), 632-636.

Kidane, A. (1990): "Mortality estimates of the 1984-85 Ethiopian famine," Scandanavian Journal of Social Medicine, 18(4), 281-6.

Kiros, G.-E., And D. P. Hogan (2001): "War, famine and excess child mortality in Africa: the role of parental education," International Journal of Epidemiology, 30(3), 447-455.

Kumar, B. (1990): "Ethiopian famines 1973-1985: a case study," in The Political Economy of Famine, Vol. II: Famine Prevention, ed. by J. Drze, and A. Sen, vol. II, pp. 173-216. Clarendon Press, Oxford.

Luo, Z., R. Mu, and Z. Xiaobo (2006): "Famine and Overweight in China.," Review of Agricultural Economics, 28(3), 296 - 304.

Maccini, S., And D. YAng (2009): "Under the Weather: Health, Schooling, and Socioeconomic Consequences of Early-Life Rainfall," American Economic Review, 99(3), 1006-1026.

Maluccio, J. A., J. Hoddinott, J. R. Behrman, R. Martorell, A. R. Quisumbing, And A. D. Stein (2008): "The impact of an experimental nutritional intervention in childhood on education among Guatemalan adults," Economic Journal, 371.

(2009): "Effect of a nutritional intervention during early childhood on economic productivity among Guatemalan adults," The Lancet, 119(537), 734763 .

Martorell, R., K. Khan, and D. Schroeder (1994): "Reversibility of stunting: epidemiological findings in children from developing countries," European Journal of Clinical Nutrition, 48, 45-47.

Meng, X., And N. Qian (2009): "The Long Term Consequences of Famine on Survivors: Evidence from a Unique Natural Experiment using China's Great Famine," Discussion paper, NBER.

Neelson, S., and T. Stratmann (2010): "Effects of Prenatal and Early Life Malnutrition: Evidence from the Greek Famine," Working Paper 2994, CESifo.

Nielsen, J., H. Jensen, P. K. Andersen, and P. Aaby (2006): "Mortality patterns during a war in Guinea-Bissau 1998-99: changes in risk factors?," Int J Epidemiol, 35, 438 - 446.

O Grada, C. (2007): "Making Famine History," Journal of Economic Literature, 45(1), 5-38. 
Pankhurst, R. (1986a): "The Ethiopian Famine: Cultural Survival's New Report," Anthropology Today, 2(3), 4-5.

(1986b): The history of famine and epidemics in Ethiopia : prior to the twentieth century. Relief and Rehabilitation Commission, Addis Ababa.

Ravelli, A., J. van Der Meulen, C. Osmond, D. Barker, and O. BlEkER (1999): "Obesity at the age of $50 \mathrm{y}$ in men and women exposed to famine prenatally.," Am J Clin Nutr., 70(5), 811-6.

Ravelli, A., J. van Der Meulen, C. Osmond, D. Barker, C. Hales, AND O. BLEKER (1998): "Glucose tolerance in adults after prenatal exposure to famine.," Lancet, 351(9097), 173-7.

RonA, R. J. (1981): "Genetic and Environmental Factors in the control of growth in Childhood," British Medical Bulletin, 37(3), 265-272.

RRC (1984): Review of the current drought situation in Ethiopia. Relief and Rehabilitation Commission, Addis Ababa.

(1985): The challenges of drought: Ethiopia's decade of struggle in relief and rehabilitation. Relief and Rehabilitation Commission, Addis Ababa.

Ruel, M. T., J. Rivera, J. P. Habicht, and R. Martorell (1995): "Differential Response to Early Nutrition Supplementation: Long-Term Effects on Height at Adolescence," .

Rutter, M. (2006): Genes and behavior: nature-nurture interplay explained. Blackwells, Malden, MA.

Segele, Z. T., And P. J. Lamb (2005): "Characterization and variability of Kiremt rainy season over Ethiopia," Meteorology and Atmospheric Physics, 89(1), 153-180.

Strauss, J., And D. Thomas (2008): "Health over the life course.," in Handbook of Development Economics, Volume IV, ed. by T. P. Schulz, and D. Thomas, vol. 4. Elsevier Press.

Webb, P., J. von Braun, and Y. Yohannes (1992): "Famine in Ethiopia: Policy Implications of Coping Failure at National and Household Levels," Discussion Paper 92, International Food Policy Research Institute (IFPRI). 


\section{B. Statistical Appendix}

Table 1: Famine and Drought, by Village

\begin{tabular}{llrrr}
\hline $\begin{array}{l}\text { Peasant } \\
\text { association }\end{array}$ & Region & $\begin{array}{r}\text { Drought } \\
\text { affected }\end{array}$ & $\begin{array}{r}\text { Drought } \\
\text { in }\end{array}$ & $\begin{array}{r}\text { W3-5 } \\
\text { 84-5 }\end{array}$ \\
\hline Haresaw & Tigray & 1.00 & 1.00 & 0.77 \\
Geblen & Tigray & 1.00 & 1.00 & 0.15 \\
Dinki & Shewa & 1.00 & 1.00 & 1.00 \\
Yetemen & Gojjam & 0.59 & 0.41 & 0.41 \\
Shumsha & Wollo & 0.93 & 0.71 & 0.64 \\
Adele Keke & Harerghe & 0.68 & 0.54 & 0.46 \\
Korodegaga & Arssi & 1.00 & 1.00 & 0.78 \\
Trurufe Ketchema & Shewa & 0.87 & 0.76 & 0.65 \\
Imdibir & Shewa & 0.83 & 0.83 & 0.83 \\
Aze Deboa & Shewa & 1.00 & 1.00 & 1.00 \\
Adado & Sidamo & 0.00 & 0.00 & 0.00 \\
Gara Godo & Sidamo & 1.00 & 1.00 & 0.76 \\
Do'oma & Gama Gofa & 1.00 & 0.86 & 0.61 \\
Debre Berhan-Milki & Shewa & 1.00 & 1.00 & 1.00 \\
D.B. -Kormargefia & Shewa & 0.25 & 0.25 & 0.13 \\
D.B. -Karafino & Shewa & 0.20 & 0.20 & 0.20 \\
D.B. -Bokafia & Shewa & 0.00 & 0.00 & 0.00 \\
\hline
\end{tabular}

Notes: Sample is the same as in descriptive statistics table below. 1) Specifically, responded 'drought' to the question "In the last 20 years has the household suffered a substantial loss of harvest through any of the following [list of potential crises]?" 2) Households were asked to list the three worst crises, this entry is positive if the household responds EC75, EC76 or EC77 (1983-85) 3) In the list from (2), household ranks EC77 (1984-85) as the worst crisis. 
Table 2: Dates of famine and cohort ages

\begin{tabular}{|c|c|c|c|}
\hline Dates & $\begin{array}{ll}\text { Famine } & \text { related } \\
\text { events } & \end{array}$ & $\begin{array}{l}\text { Cohort birth } \\
\text { and age in } \\
\text { famine }\end{array}$ & $\begin{array}{l}\text { Age } 2004 \\
\text { survey }\end{array}$ \\
\hline Sept 78 - Sept 80 & $\begin{array}{l}\text { Relatively normal har- } \\
\text { vest }\end{array}$ & \multirow[t]{2}{*}{$\begin{array}{l}\text { "Born before } \\
\text { Famine" (Oldest } \\
\text { cohort aged } \\
37-72 \text { months in } \\
\text { famine) }\end{array}$} & \multirow[t]{2}{*}{$23-24-25$} \\
\hline Sept 80 - Sept 81 & $\begin{array}{l}\text { Relatively normal har- } \\
\text { vest }\end{array}$ & & \\
\hline Sept 81 - Sept 82 & $\begin{array}{l}\text { Bumper rains and har- } \\
\text { vests in many places } \\
\text { during this year }\end{array}$ & \multirow[t]{2}{*}{$\begin{array}{l}\text { "Just before } \\
\text { famine" Age } \\
12-36 \text { months in } \\
\text { famine }\end{array}$} & \multirow[t]{2}{*}{$21-22$} \\
\hline Sept 82 - Sept 83 & $\begin{array}{l}\text { Drought, crop failure, } \\
\text { war spread in the } \\
\text { north }\end{array}$ & & \\
\hline Sept 83 - Sept 84 & $\begin{array}{l}\text { Peak of the famine } \\
\text { continues through } \\
\text { two years- widespread } \\
\text { hunger, death. }\end{array}$ & \multirow[t]{2}{*}{$\begin{array}{lr}\text { "Born } & \text { during } \\
\text { Famine" } & \text { Born } \\
\text { and in-utero } \\
\text { during severe } \\
\text { shock period }\end{array}$} & \multirow[t]{2}{*}{$19-20$} \\
\hline Sept 84 - Sept 85 & $\begin{array}{l}\text { Famine peaks in many } \\
\text { areas }\end{array}$ & & \\
\hline Sept 85 - Sept 86 & $\begin{array}{l}\text { Normal Meher rains } \\
\text { (Aug/Sep 86) marked } \\
\text { the end of drought }\end{array}$ & \multirow[t]{2}{*}{$\begin{array}{l}\text { "Born } \\
\text { ter af- } \\
\text { (Youngest co- } \\
\text { hort) }\end{array}$} & \multirow[t]{2}{*}{ 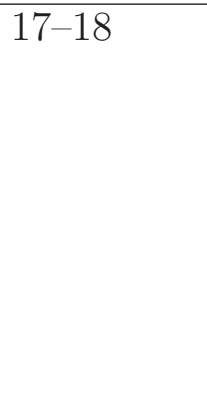 } \\
\hline Sept 86 - Sept 87 & $\begin{array}{lcr}\text { Normal } & \text { year } & \text { but } \\
\text { some problems in } \\
\text { certain villages } & \text { this } \\
\text { year) } & & \end{array}$ & & \\
\hline
\end{tabular}

Notes: Dates run from September to September to match the Ethiopian calendar which begins on 11th September. Information on dates is discussed and referenced in the main text. 
Table 3: Height by cohort and famine shock

\begin{tabular}{lrrrrr}
\hline \hline Cohort & All & Unaffected & Affected & $\begin{array}{r}\text { T-test of diff } \\
\text { p-value }\end{array}$ & N \\
\hline Youngest group & & & & & \\
(born after famine) & 155.456 & 155.602 & 155.356 & $0.119(0.45)$ & 130 \\
In utero-12months in famine & 159.842 & 158.802 & 160.576 & $-0.916(0.18)$ & 133 \\
Aged 13-36 months in famine & 161.683 & 163.119 & 160.965 & $0.917(0.18)$ & 111 \\
Aged 36 months + in famine & 163.422 & 161.765 & 164.571 & $-1.375(0.09)$ & 105 \\
\hline
\end{tabular}

Notes: Sample is children aged 17-25 years old in 2004, definition of cohorts in table 2, definition of drought shock in table 1 . P-value of one-sided t-test in brackets.

Table 4: Summary statistics

\begin{tabular}{lccc}
\hline \hline \multicolumn{1}{c}{ Variable } & Mean & Std. Dev. & N \\
\hline Height in centimetres, 2004 & 159.863 & 11.507 & 479 \\
Body mass index, 2004 & 19.356 & 3.477 & 478 \\
School grade attained & 4.582 & 3.604 & 364 \\
Dummy: finished primary & 0.313 & 0.464 & 479 \\
Height-for-age, 1994 & -2.151 & 1.62 & 421 \\
Dummy: Female=1 & 0.436 & 0.496 & 479 \\
Youngest group (born after famine) & 0.271 & 0.445 & 479 \\
Aged 0-1 in famine & 0.278 & 0.448 & 479 \\
Aged 2-3 in famine & 0.232 & 0.422 & 479 \\
Oldest group (aged 4+ in famine) & 0.219 & 0.414 & 479 \\
Household drought shock & 0.608 & 0.489 & 479 \\
Birth order & 3.309 & 1.383 & 479 \\
\hline
\end{tabular}

Notes: Sample is children aged 17-25 years old in 2004, definition of cohorts in table 2, definition of drought shock in table 1. 


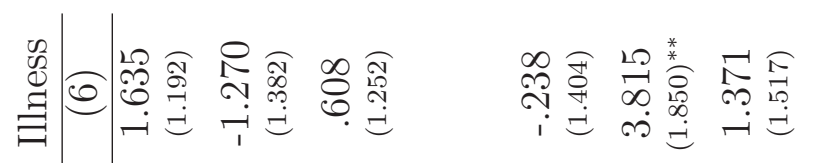

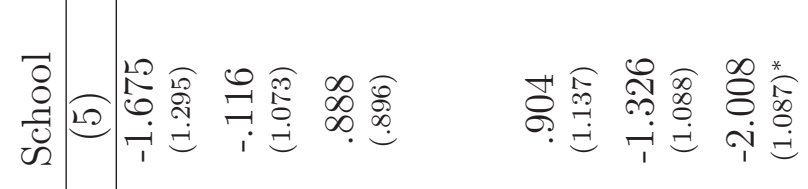

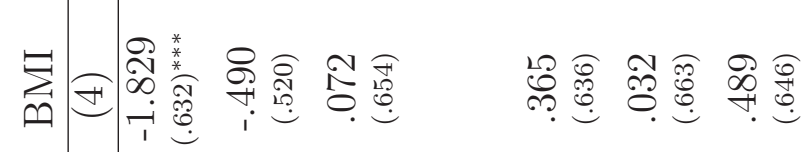

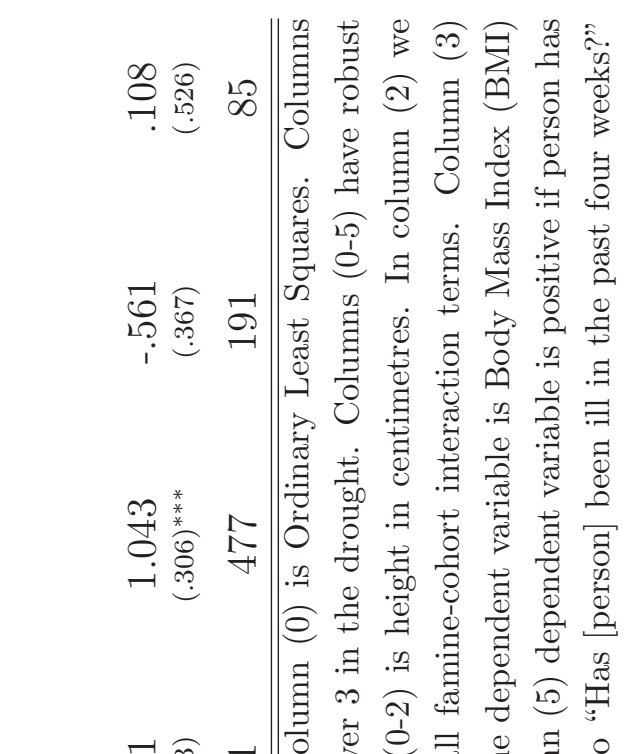

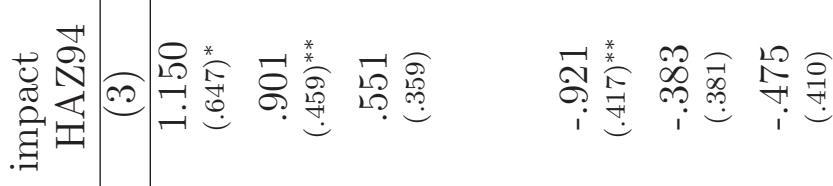

罗

章

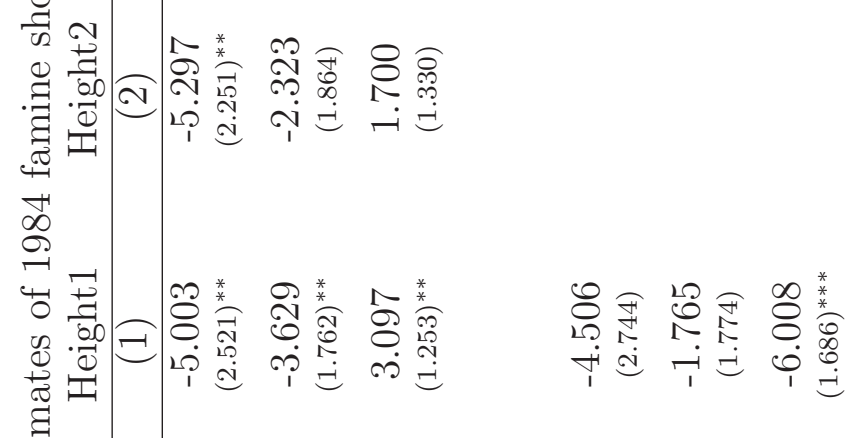

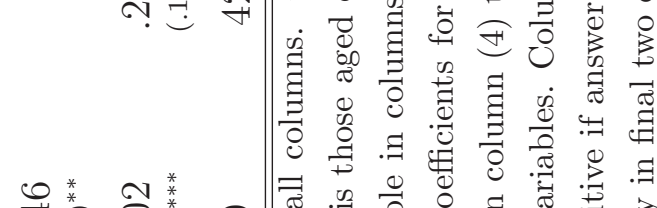

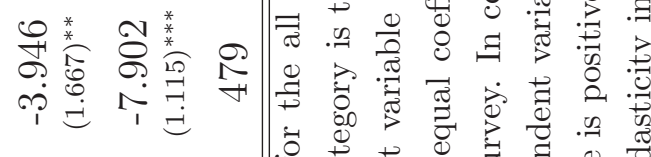

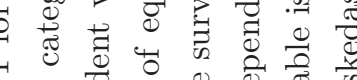

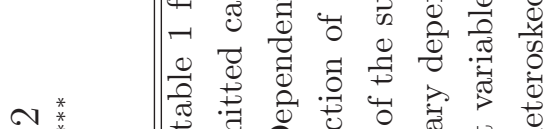

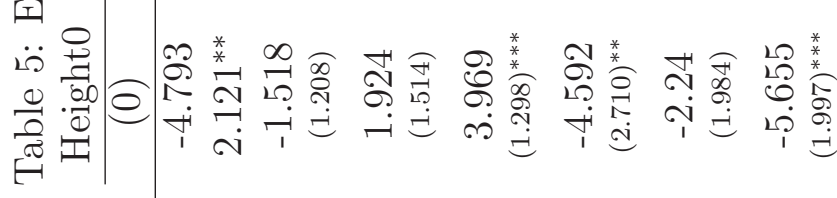

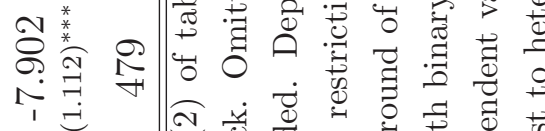

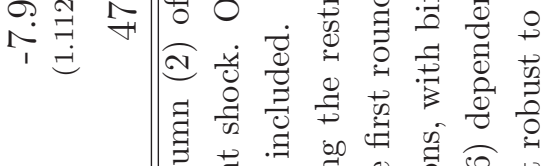

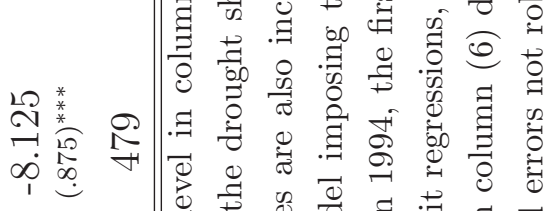

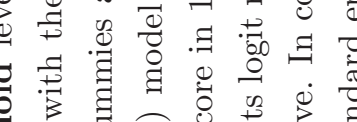

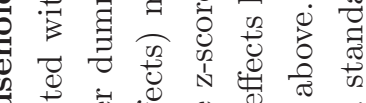

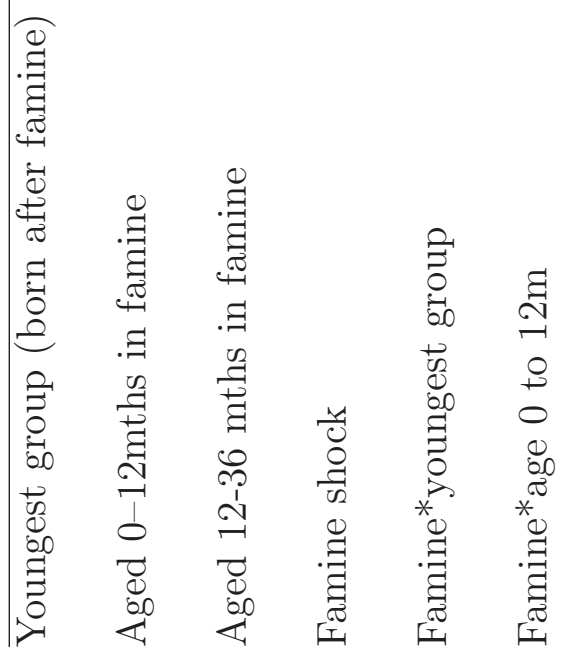

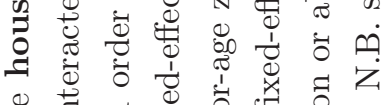

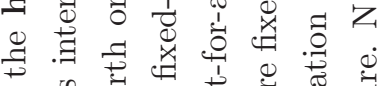

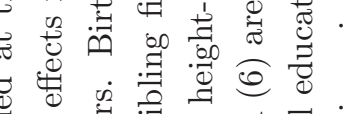
至

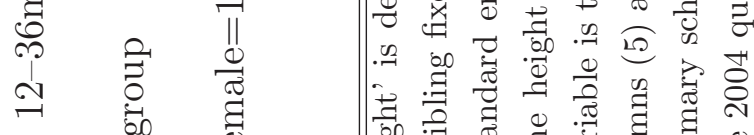

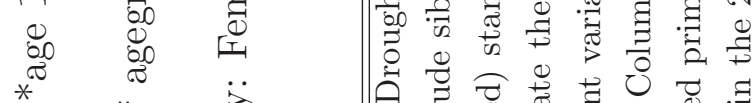

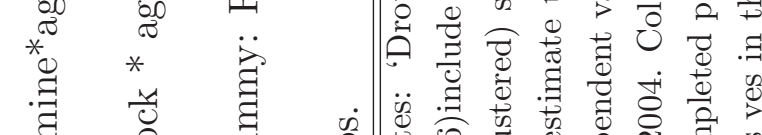

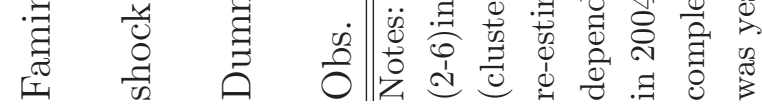


Table 6: Descriptive statistics: Household heads, 2004

\begin{tabular}{lccc}
\hline \hline \multicolumn{1}{c}{ Variable } & Mean & Std. Dev. & N \\
\hline Height in centimetres & 163.83 & 9.281 & 1144 \\
Gender (female=2) & 1.295 & 0.456 & 1144 \\
Age in years & 50.557 & 15.121 & 1144 \\
Highest school grade attained & 3.877 & 6.283 & 1144 \\
Dummy: attended school up to primary & 0.141 & 0.348 & 1144 \\
Dummy: finished primary school (or above) & 0.252 & 0.434 & 1144 \\
Household Size & 5.746 & 2.534 & 1144 \\
Female children 5-15 & 0.921 & 0.989 & 1144 \\
Female children under 5 & 0.339 & 0.563 & 1144 \\
Male children under 5 & 0.32 & 0.567 & 1144 \\
Male children 5-15 & 0.92 & 0.998 & 1144 \\
Female elderly & 0.167 & 0.405 & 1144 \\
Male elderly & 0.199 & 0.49 & 1144 \\
Log total annual income & 7.513 & 0.974 & 1144 \\
scriptive statistics for sample of household heads in 2004 used for the regressions of household \\
come on human capital of household heads.
\end{tabular}

Table 7: Human capital regressions, 2004

\begin{tabular}{lcc} 
& Income1 & Income2 \\
\cline { 2 - 3 } & $(1)$ & $(2)$ \\
\hline Height, centimetres & .009 & .010 \\
Gender (female=2) & $(.003)^{* * *}$ & $(.003)^{* * *}$ \\
Age, years & -.162 & -.176 \\
& $(.074)^{* *}$ & $(.075)^{* *}$ \\
Square of age, years & -.002 & -.006 \\
Highest school grade attained & $(.009)$ & $(.009)$ \\
& .00006 & .00008 \\
School squared & $(.00009)$ & \\
& $.000009)$ \\
& $(.019)^{* * *}$ &
\end{tabular}

Any school but not complete primary $\quad .078$

$(.075)$

Completed primary school $\quad .171$

$(.059)^{* * *}$

Obs.

1144

1144

Notes: ${ }^{* *}$ Significant at $1 \%,{ }^{* *}$ Significant at $5 \%,{ }^{*}$ Significant at $10 \%$. Both regressions OLS with village fixed-effects. Dependent variable in both columns is $\log$ of household income in 2004. 